\title{
The Investigation on the Engineering University Students' Entrepreneurial Quality
}

\author{
Cheng Zhilong ${ }^{a}$, Ding Hao ${ }^{b}$ \\ Educational Department of Bengbu College, Bengbu, China, 233030 \\ a527105378@qq.com, ${ }^{a} 346490922 @ q q . c o m$
}

Keywords: engineering major; university students; entrepreneurial quality; investigation

\begin{abstract}
With the help of the questionnaire by ourselves, the situation of the entrepreneurial quality of 600 universities students who are from different areas in Anhui province are investigated. The results are as follows:1. The general situations of Engineering college students' entrepreneurial quality are not positive. 2 . The differences of university students' entrepreneurial quality are caused by these demographic variables of sex, grade. 3. The students who major in electronic information science scores higher than those majoring in mechanical engineering, physical chemistry, biological science in four selected engineering fields. 4 . The conclusion of the study provides a scientific basis for culturing the ability of establishing a business of the university students majoring in engineering.
\end{abstract}

\section{Introduction}

Quality is the prerequisite for the development of psychological activities. Although there are lots of explanations of different subjects. The tendency exists that the quality bases on the fact of psychology and physiology, with its natural attributes as the basic premise. The differences of individual quality are determined by the psychological and physiological maturity level, therefore, the understanding of people's quality should take the physical and psychological organization and the quality level as the premise. Chen Yan(2006) ${ }^{[1]}$ thinks the ability of establishing a business refers to entrepreneurs having comprehensive quality involving various abilities, characters, habits and so on. According to statistics, "the ratio of Chinese students choosing to establish a business is 5\%, involving the successful rate of about 3\%, the figure is 7 times the American successful rate of $27 \%$."

${ }^{[2]}$ Researchers think engineering students' entrepreneurial quality is the basic condition when establishing a business. Currently, the direction of universities' carrying out the reform of Quaity Education is culturing the engineering students' entrepreneurial quality, which provides a most important significance for the promotion of Chinese higher education and the development of the social economy. Based on this, the investigation of the situation of university students' entrepreneurial quality, in order to fully understand the present overall situation and basic characteristics of engineering students' entrepreneurial quality, provide a scientific basis for culturing their entrepreneurial quality.

\section{Research Methods}

\subsection{Object of study}

Engineering college students from six colleges in Anhui province participated in this survey from northern Anhui to its South, including Bengbu College, Tongling College ,Chizhou College, Huangshan College, Tongcheng Normal Vacational School, Hefei College and others. The project in the design of questionnaire covers gender, grade, professional categories and other demographic variables. The test distribution is shown in Table 2 .

\subsection{Research Tools}

With the help of the questionnaire by ourselves, the questionnaire has 24 questions in total. By questioning way, according to the needed alternative answers A, B, C, D, E. One scores 1 point when correctly answering it, otherwise, don't score. The full mark is 24 points. The questionnaire 
researches the engineering university students' entrepreneurial quality from the following six aspects: the attitudes and understanding, preparation, the approach to getting the entrepreneurial knowledge, the acquision of all types of relevant activities, influence factors and confusion, beneficial policy and necessary ability.

\subsection{Data Processing}

The questionnaire data processing use SPSS15 statistical analysis software to describe situation, as well as the statistical inference about difference comparison.

\section{Results}

\subsection{Overall situation of engineering university students' entrepreneurial quality}

Table 1 The overall distribution table of university students' entrepreneurial quality

\begin{tabular}{llllll}
\hline The range of scores & $\begin{array}{l}\text { The score range } \\
\text { between } 1 \text { and } 8\end{array}$ & $\begin{array}{l}\text { The score range } \\
\text { between } 9 \text { and } 16\end{array}$ & $\begin{array}{l}\text { The score range } \\
\text { between } 17 \text { and } 24\end{array}$ & Total \\
\hline Number of people & 239 & 270 & 91 & 600 \\
percentage & 39.8 & 45.0 & 15.2 & 100.0 \\
\hline
\end{tabular}

600 University students being investigated by using the questionnaire, the result showed more than $39 \%$ of the engineering university students score $1-8$ points, only $15.2 \%$ of them score more than 17 points.

\subsection{Engineering university students entrepreneurial quality score difference comparison}

3.2.1 Engineering university students entrepreneurial quality score Gender difference

Took the questionnaire score as the test variables, gender as grouping variables, the results of the independent sample $t$-test showed that there is a significant difference between boys and girls $(\mathrm{t}(598)$ $=5.02, \mathrm{p}=0.000$ ) (Table 2).

Table 2 Engineering university students entrepreneurial quality score statistics

\begin{tabular}{lllll}
\hline Grouping variable & dimensions & $\mathrm{N}$ & Average & Standard deviation \\
\hline \multirow{2}{*}{ gender } & boys & 399 & 11.19 & 4.71 \\
& girls & 201 & 9.22 & 4.11 \\
\cline { 2 - 5 } grade & freshman & 159 & 8.82 & 3.997 \\
& sophomore & 156 & 9.40 & 3.762 \\
& junior & 159 & 10.54 & 4.070 \\
& senior & 126 & 14.07 & 5.027 \\
\cline { 2 - 5 } Professional categories & Mechanical engineering & 155 & 10.35 & 4.233 \\
& Electronic info-science & 153 & 11.71 & 5.231 \\
& Physical chemistry & 144 & 10.07 & 4.324 \\
& Biological science & 128 & 10.20 & 4.539 \\
\hline
\end{tabular}

3.2.2 Engineering university students entrepreneurial quality score Grade difference

Took the questionnaire score as the test variables, grade as grouping variables, one-way ANOVA analysis results showed that the big difference of entrepreneurial quality in different grades $(\mathrm{F}(3,596)=42.492, \mathrm{p}=0.000)$. By multiple comparisons, there are no significant differences between freshman and the sophomore but the differences between the junior and the senior is on the contrary. With higher grade, the quality increased year by year. The score will reach to the highest point when it comes to the fourth grade. 
Table 3 Multiple comparison of variance of Engineering university students entrepreneurial quality score

\begin{tabular}{llll}
\hline (I) grade & $(\mathrm{J})$ grade & Mean difference $(\mathrm{I}-\mathrm{J})$ & significance \\
\hline \multirow{3}{*}{ freshman } & sophomore & -.586 & .216 \\
& junior & $-1.723^{*}$ & .000 \\
& senior & $-5.254^{*}$ & .000 \\
\cline { 2 - 4 } sophomore & freshman & .586 & .216 \\
& junior & $-1.137^{*}$ & .016 \\
& senior & $-4.668^{*}$ & .000 \\
\cline { 2 - 4 } junior & freshman & $1.723^{*}$ & .000 \\
& sophomore & $1.137^{*}$ & .016 \\
& senior & $-3.531^{*}$ & .000 \\
\cline { 2 - 4 } senior & freshman & $5.254^{*}$ & .000 \\
& sophomore & $4.668^{*}$ & .000 \\
& junior & $3.531^{*}$ & .000 \\
\hline
\end{tabular}

$* \mathrm{p}<0.05$

3.2.3 The professional differences of engineering university students' entrepreneurial quality score

Took the questionnaire score as the test variables, professional categories as grouping variables, one-way ANOVA analysis results showed that the obvious difference exists in different majors

$(\mathrm{F}(3,596)=4.326, \mathrm{p}=0.002)$. Analysis of variance for multiple comparisons showed (using LSD test) the evident difference between electronic info-science and other specialized fields and there are no significant differences between mechanical engineering, physical chemistry, and biological science.

\section{Discussion}

\subsection{Engineering university students overall quality status analysis}

The statistical analysis of engineering university students' entrepreneurial quality showed their overall situation is worrying owing to about $84 \%$ of them getting scores below 16 . Zeng yuan and $\mathrm{Hu}$ Mingshan(2011) ${ }^{[3]}$ pointed out there are many factors causing the bad situation: Spirits of entrepreneurship, knowledge, psychological quality and so on. The lack of entrepreneurial quality is the core, which is consistent with the conclusion of this study.

\subsection{The Difference Analysis of engineering university students' entrepreneurial quality}

With demographic variables (grade, major categories) as grouping variables, the statistical analysis results showed the entrepreneurial quality of the male were obviously higher than the female. At the sametime, scores increased gradually with the higher grade. Entrepreneurship has a high risk and a high return. Studies showed that the male had a higher risk-taking propensity, which may explain the male get higher scores. Colleges and universities should organize the relevant education curriculum, which not only contribute to entrepreneurship and employment, but also the formation of "the direct driving force" for the development of the national economy. [4] "Higher education for 21 century: vision and action of the world declaration" pointed out: "Higher education should mainly concerned on fostering entrepreneurial skills and initiative spirit in order to fascinate the employment of graduates. Graduates are no longer the seekers but the creators of the job. "At present, our country promote entrepreneurial education from national strategy level, which could explain the senior scored higher than the junior[5]. 


\section{Conclusions and Countermeasures}

The overall situation of engineering university students' quality is poor. There is a significant difference in different genders, grades, majors. The conclusion of the research provides some information for reference.

First, correct attitude towards education, change the education idea, set up the applied talents training consciousness, establish the pioneering position of entrepreneurial education training creative talents.

Second, a comprehensive entrepreneurial education, strengthen the entrepreneurial practice guidance, encourage the engineering university students change the concept to employment foster the entrepreneurial quality.

Third, develop the function of the second class, organize extensive entrepreneurial training, use the students' social activities and three rural areas as channel, encourage students take part in social practice in which to enhance entrepreneurial ability.

Fourth, industry and research integration, create business park, establish business base, play the practice and employment base's role, construct the engineering students' entrepreneurial service platform system.

\section{Reference}

[1]Zhang Jianmin, Yu Xiaofei, Fan Wenxing, Yang Shujuan. University students' entrepreneurial quality, Improve ability: Research situation and expectation, Economic research periodical. 2011(04): 289-291.

[2]Mo Fan. The research of university students' entrepreneurial quality and the main approach of developing entrepreneurial quality. Educational periodical, 2011(08): 48-50.

[3]Zong Yuan, Hu Mingshan. The situation of the university students' entrepreneurial quality, problems and the research of education countermeasure. Jiangxi University of Science and Technology's Journal, 2011(04):34-36.

[4]Lin Li. The analysis of training university students' entrepreneurial quality. Jouranl of Ideological and theoretical education, 2010(08):114-117.

[5]Zhou Jing. Higher students' entrepreneurial education and construction of its system. Journal of Qinghai Normal University, 2011(06): 146-169. 